\title{
Ensino de Psicologia: limites do atual paradigma e a complementaridade do paradigma da complexidade
}

\section{Psychology Teaching: limits of the current paradigm and complementarity of the complexity paradigm}

\author{
Solange Martins Oliveira Magalhães ${ }^{1}$
}

\begin{abstract}
RESUMO
O presente artigo, de natureza teórica, tem por objetivo trazer ao debate acadêmico a importância da articulação do paradigma da complexidade ao ensino de Psicologia. Destacamos essa interlocução como inovadora no contexto da formação docente. Enfatizamos alguns limites do paradigma atual e a complementaridade do paradigma da complexidade ao Ensino de Psicologia. Essa reflexão frente à prática formadora marca a busca de novas bases epistemológicas que estimulem a (trans)formação dos sujeitos pessoal e coletivamente. Longe de dar respostas prontas e acabadas, lançamos mão da condição de análise crítica e reflexiva, postura que visa à reestruturação dos caminhos percorridos pela Psicologia na formação docente.
\end{abstract}

Palavras-chave: formação docente; complexidade; ensino de Psicologia.

\begin{abstract}
This article, of theoretical basis, aims to bring to the academic debate the importance of articulating the paradigm of complexity to the teaching of psychology. I highlight this dialogue as an innovator one in the context of teacher education. I stress some limits of the current paradigm and the complexity paradigm complementarity to the Teaching of Psychology. This reflection in face of the forming practice marks the search for new epistemological foundations to encourage the (trans)formation of the subjects personally
\end{abstract}

${ }^{1}$ Doutora em Educação. Professora do Programa de Pós-Graduação em Educação da Faculdade de Educação da Universidade Federal de Goiás (UFG), Goiás, Brasil.E-mail: solufg@hotmail.com 
and collectively. Far from finished and ready answers, I use the condition of critical and reflective analysis approach that aims at restructuring the paths of psychology in teacher education.

Keywords: teacher education; complexity; Psychology teaching.

\section{Introdução}

É comum ouvirmos falar que estamos vivendo um momento de crise e de mudanças paradigmáticas, em particular, da crise da educação. Essa situação tem incitado a profusão de novas propostas, inclusive paradigmáticas, que sugerem redimensionamento, não só da educação, mas também da formação, profissionalização e do trabalho docente, a partir de novas bases epistemológicas.

A profusão de propostas, sobretudo no campo da educação, são evidências práticas da inquietação, vindas das mais diversas filiações teóricas e ideológicas, dentre as quais é possível citar: educação em direitos humanos (BRASIL, 2007), educação em valores (MARTÍN; PUIG, 2010), cultura de paz e educação para paz (JARES, 2003), educar para a arte da solidariedade ou para a sensibilidade solidária (ASSMANN, 1998), a perspectiva de educar na biologia do amor (MORAES, 2003), educação e humanizar o infra-humano (ARRUDA, 2003), educar com o coração (PUEBLA, 1997), educar para a esperança (FREIRE, 1997a), sete saberes necessários à educação do futuro (MORIN, 2007), educação transdisciplinar (MAGALHÃES, 2011), de algum modo todas representam um movimento inovador ${ }^{2}$ da educação, e recomendam que seja por meio dela ser possível a transformação da nossa sociedade. Alega-se que essa é a única forma de instituir-se uma "ética planetária", que acelere o advento de uma cidadania mundial, conforme anunciaram Petraglia e Vasconcelos (2009, p. 65). Todas essas contribuições são evidências de que não podemos dizer que vivemos

2 Apesar do termo inovação carregar em sua geração o ônus da complexidade, às vezes até essência neoliberal, entendemos que significa promover a ruptura com a forma tradicional de ensinar e aprender e/ou com os procedimentos acadêmicos inspirados nos princípios positivistas da ciência moderna. Isso envolve promover a mediação entre as subjetividades dos envolvidos e o conhecimento, englobando a dimensão das relações e da sensibilidade, do respeito mútuo, dos laços que se estabelecem entre os sujeitos e o que se propõe a conhecer. Envolve estimular posições que caraterizam formas diferentes de pensar e agir que dêem suporte a uma concepção político-social dos princípios do controle social buscando sua superação (CUNHA, 2007). 
exatamente um período de normalidade dos processos formativos, tomando de empréstimo a consagrada expressão kuhniana ${ }^{3}$ (KUHN, 1996).

Com efeito, vivemos um momento crítico e é dessa percepção mesma que parte essa reflexão, mais especificamente da necessária transformação da sala de aula universitária diante da chamada crise paradigmática. Nossa percepção deste momento não é exatamente a mais comum: problema, destruição, pessimismo, ao contrário, a própria abundância de novas propostas indica que, em períodos de crise, há uma forte percepção de limites, de esgotamento dos padrões estabelecidos, legitimados ou aceitáveis, mas há também, mesmo que seja paradoxal, uma perspectiva de renovação, de transformação, de (re)criação. Se vários "perigos" são associados à crise da educação, esses andam de braços dados com as oportunidades, num verdadeiro câmbio inovador. Parece muito sábio, nesse sentido, o tradicional simbolismo do I Ching, livro chinês muito antigo, quando representa crise com dois hexagramas, indicando simultaneamente perigo e oportunidade.

Entretanto, como adverte Morin (2007), ainda carecemos de "operadores cognitivos" que nos ajude no entendimento de pares aparentemente inconciliáveis e antagônicos, como: ordem-desordem, sujeito-objeto, razão-emoção, destruição-construção, perigo-oportunidade, sem eles fica difícil compreender e lidar com as incertezas advindas da completa inconstância sucedida de novas relações binárias. Entender pares inconciliáveis, conforme descrito pela Teoria da complexidade, exige o desenvolvimento do operador cognitivo dialógico, o qual nos ajuda a romper com a ideologia da ordem, e sua ideia reacionária, segundo a qual toda inovação, toda novidade, toda transformação significa degradação, perigo e morte.

Ao contrário, como sugere o movimento do simbolismo do I Ching, aquilo que aparentemente parece excluído, “[...] imponderável, aquilo que perturba o sistema pode ser extremamente significativo, revelador, desencadeante, acelerador, motivador [...]" (MORIN, 1995, p. 189). As oportunidades estão presentes e já se esboçam nas ideias, reflexões e nas práticas de alguns educadores, e a pertinência desse movimento inovador ganha mais relevância quando se recorda que o sistema educacional é extremamente limitado em seus impactos, e perverso na perspectiva social.

Ainda que não estejam consolidadas totalmente, e mesmo que seja de maneira periférica, esse movimento inovador também perpassa a universidade,

${ }^{3}$ Foi Thomas Kuhn (1996, p. 60) quem deu uma ampla dimensão à noção de paradigma, ele definiu como uma estrutura absoluta de pressupostos que alicerça uma comunidade científica. Entretanto, sabemos que, gradualmente, esse paradigma vem perdendo sua capacidade de explicar uma realidade, cada vez mais complexa, heterogênea e plural. 
sobretudo a pública. Com ele, ou a partir dele, a universidade ganha novo ímpeto ao procurar resgatar, em mais um "renascimento da fênix", a importância do seu locus como essencialmente humanizador, mantenedor de ideais e metas, no que se refere à formação, reflexão, criação e crítica, que mostram-se inseparáveis da ideia de democracia e de democratização do saber (CHAUÍ, 2003).

Nesse sentido, valorizar o domínio das oportunidades significa não obstaculizar a riqueza de relações que podem ser estabelecidas via jovens propostas educacionais inovadoras, nem negar imediatamente sua capacidade de construção de uma educação comprometida com a "transformação e a emancipação humana" (PETRAGLIA; VASCONCELOS, 2009, p. 74). Podemos dizer que estamos diante da chance de rever nossos grandes sistemas interpretativos e explorar ao máximo as possibilidades de sermos abertos à renovação, basta tentarmos, no mínimo, nos manter distanciados das paralisantes deformações ideológicas de nossas teorias legitimadas.

Não se trata aqui de invalidar o paradigma clássico, mas sim reconduzi-lo aos seus limites e assumir a possível complementaridade de novos paradigmas. Acredita-se que os processos de inovação ${ }^{4}$ educacional em curso passam pela questão paradigmática, essa pode ser ponderada a partir da recondução humilde aos seus atuais limites, e pela abertura à complementaridade, proposta pelos novos paradigmas. Talvez nesse processo se possa observar quais são os avanços para aprová-los e onde estão os limites para criticá-los e superá-los.

Essa parece ser uma postura crítica reflexiva, que faz com que as duas leituras paradigmáticas não se excluam mutuamente, ao contrário, promove-se um revigorado questionamento dos quadros gnoseológicos (pensamento da realidade) e ontológicos (natureza da realidade). Também é possível rever os princípios fundamentais que regem a produção do conhecimento, os fenômenos e o pensamento, logo, da mesma forma, tem-se a oportunidade de superar entraves teórico-metodológicos diante dos objetos de estudo que, para serem compreendidos, em sua complexidade, exigem uma nova perspectiva epistemológica.

A expansão das oportunidades abertas, diga-se novamente inovadoras, também pode revitalizar crenças, valores, saberes, e ajudar a questionar a neutralidade, constância e estabilidade dos atuais conhecimentos científicos. O "dobrar-se sobre si mesmo", refletir, como uma maneira de pensar os próprios pressupostos, pode redefinir, em última instância, práticas fundamentais e indis-

${ }^{4}$ Nosso conceito de inovação vai de encontro ao de Lucarelli (1997), no qual inovação deve procurar alterar as relações unilaterais de uma classe tradicional. Inovar significa alterar o sistema intersubjetivo do estudante como sujeito, ainda que a aula universitária não esgote as estruturas subjetivas. Somamos as ideias de progressão, de ordem, de novo, de intencionalidade, de melhoria sensível, de sedução, de aperfeiçoamento consciente, de emancipação. 
pensáveis nas atuais lides acadêmicas, já tão testemunhadas por vários pensadores (BOURDIEU, 2001; GADOTTI, 2000; GUARECHI, 2003; SANTOS, 2004a).

No âmbito dessa discussão, recordamos um trecho publicado no artigo de Guareschi (2003, p. 246), no qual ele faz uma reflexão sobre a Filosofia no seu papel de mudar o mundo. Ele destaca uma importante afirmação de Marx e Engels (1977), nas Teses sobre Feuerbach, em que ele diz que "os filósofos tinham tentado interpretar o mundo; a questão agora era transformá-lo". Apesar de não estar discutindo aqui a importância da Filosofia, entendemos que a questão é a mesma, passa pelo interpretar o mundo, tentar compreendê-lo, para transformá-lo. Essa ideia é complementada por Freire (1997b) quando afirma que também passa pela palavra, para ele, dizer a palavra transforma o mundo porque ao dizer a própria palavra os sujeitos começam a construir conscientemente seus próprios caminhos.

Por tudo isso e por nos encontrar na desafiadora prática do ensinar-aprender no campo da formação de professores, pensamos ser um momento oportuno para refletir sobre a forma como tem sido trabalhado o ensino de Psicologia, no centro de uma das mais progressistas proposições epistemológicas na atualidade: a Teoria da Complexidade; suas proposições colocam os limites do atual paradigma, ao mesmo tempo em que nos desafia a elaborar novas práticas pedagógicas que sejam comprometidas com a expansão do pensamento.

Nesse sentido, almejamos um ensino de Psicologia que ajude a construir um processo de formação integral dos sujeitos. Em sua proposta de formação integral, Torre e Barrios (2002, p. 78) concebem a formação como mudança, e esta tem pressupostos teóricos que a balizam como organizadora conceitual da realidade e como princípio de construção do conhecimento. Para eles, a educação integral promove a consciência como construto que faz presente o que estava ausente, o visível e o invisível, o possível e o imaginário, a confrontação ou tensão inferencial que está na origem de toda mudança. Nessa proposta temos a "complexidade como qualidade inerente à ação, ao pensamento e sentimento humanos [...] a comunicação como veículo de expressão e realização que [...] em seu sentido mais amplo, nos humaniza".

\section{Os limites do atual paradigma e a complementaridade do paradigma da Complexidade em Morin}

Nesse viés, o entendimento da complexidade que se propõe extrapola a educação em sentido estrito, requer reflexões mais amplas no que diz respeito 
à produção do conhecimento e às metas da formação humana, também exige desvendar a "ingênua neutralidade" com que enfocamos as concepções epistemológicas que sustentam nossa prática, entendendo que essas não estão apenas submetidas à lógica interna de seus campos, mas sim, às forças sociais que definem fronteiras e delimitação de jogos de poder. Essa discussão tende ser esvaziada nos campos formativos, Boaventura Santos (2004b, p. 50-58) é mais incisivo ao afirmar que somente a reflexão epistemológica acerca do conhecimento científico pode mostrar que o suposto rigor científico exigido "marginalizou" tudo o que não pode ser explicado pela razão, gerando sérios limites que exigem novamente uma "profunda reflexão epistemológica" que nos ajude a superar uma prática reprodutiva, mesmo dando suporte a um discurso crítico.

Se assim for, é necessário uma nova e motivada perspectiva de conhecimento que liga-se a um novo paradigma. Capra (1997, p. 17) afirma que um "paradigma significa a totalidade de pensamentos, percepções e valores que formam uma determinada visão de realidade, uma visão que é a base do modo como uma sociedade se organiza". No caso do novo paradigma emergente, Edgar Morin (2007) o definiu, na obra "Os sete saberes necessários à educação do futuro", como paradigma da complexidade.

Pode-se dizer que o paradigma da complexidade surgiu da necessidade de se produzir conhecimento sob um novo enfoque, a partir de uma rica e diversificada reflexão epistemológica, cujas bases se assentam numa prática científica mais aberta, com convergência de conhecimentos para sua constituição em rede, num sistema integrado que reconhece que o mundo tem múltiplas conexões em interdependência, o que configura um movimento de natureza inter/ transdisciplinar (CAPRA, 2000; NICOLESCU, 2000, 2001, 2006; DELORS, 2000; MORIN, 2002a, 2007; SOUZA, 2008; ALMEIDA; PETRAGLIA, 2011).

Frente ao espaço epistemológico da simplificação, sobretudo no campo da experiência acadêmica, esse novo caminho causa perturbação, pois propõe uma nova via paradigmática que exige o pensar juntos. Nesta mesma ordem de ideias, o complexo de Morin não se trata do que é complicado, na sua etimologia, complexus significa o que foi tecido em conjunto.

[...] de fato, há complexidade quando elementos diferentes são inseparáveis constitutivos do todo (como o econômico, o político, o sociológico, o psicológico, o afetivo, o mitológico), e há um tecido interdependente, interativo e retroativo entre o objeto de conhecimento e seu contexto, as partes e o todo, o todo e as partes, as partes entre si. Por isso a complexidade é a união entre a unidade e a multiplicidade (MORIN, 2007, p. 38-39). 
Nesta land of man (and women) onde a realidade se organiza de modo complexo, requer um pensamento também complexo para entendê-la; para entender que os fenômenos são, ao mesmo tempo, complementares, concorrentes e antagonistas; para que se respeite as coerências diversas que se unem em dialógicas e polilógicas e, que torne os sujeitos capazes de enfrentar a incerteza e a contradição por várias (e até novas) vias. Esse tipo de pensamento, segundo o paradigma da complexidade:

[...] deve ultrapassar as entidades fechadas, os objetos isolados, as idéias claras e distintas, mas também não se deixar enclausurar na confusão, no vaporoso, na ambigüidade, na contradição. Ele deve ser um jogo/trabalho com/contra a incerteza, a imprecisão, a contradição. Sua exigência lógica deve, pois, ser muito maior que aquela do pensamento simplificante, porque ele combate permanentemente numa 'terra de ninguém', nas fronteiras do dizível, do concebível, do alógico, do ilógico (MORIN, 2007, p. 387, grifos do autor).

Essa ideia é complementada por Moraes (2012), quando ela afirma que a complexidade pode ser compreendida como um princípio regulador do pensamento e da ação; aquilo que não perde de vista a realidade dos fenômenos; que não separa a subjetividade da objetividade; não exclui o espírito humano, o sujeito, a cultura e a sociedade. O olhar complexo sobre os fenômenos exige abertura epistemológica, esta estende a noção de sistema um pouco mais além da física e da biologia, ajudando a compreender não apenas a natureza ordenada/ desordenada da matéria e o funcionamento dos sistemas vivos, mas também as organizações sociais como unidades complexas.

A reparadigmatização proposta por Morin (2007, p. 381) se funda numa nova lógica que incita a distinguir e fazer comunicar, em vez de isolar e disjuntar; a conceber a unidade-multiplicidade dos objetos de estudo em vez de a heterogeneizar em categorias separadas ou de homogeneizar numa totalidade indistinta. Morin instiga a dar conta dos caracteres multidimensionais dos objetos de estudo, inclusive do homem e sua realidade.

Um ponto central dessa reparadigmatização refere-se à possibilidade de complementaridade do paradigma atual ao campo de estudos da Psicologia. Por ser um processo dinâmico de construção, nos abre as portas da lógica da articulação e da abertura frente à lógica do fragmento, o que possibilita repensar conceitos como: o pensar, a identidade, a unidade, o ser, o objeto, a sociedade, o homem, o conhecimento. 
Nesse sentido, iniciamos destacando que se a lógica clássica mostra-se insuficiente, não podemos prescindir dela. Com o pensamento complexo pode-se esclarecer que não é possível superar as contradições, tampouco podemos deixá-las de lado, o que pode ser feito é dar-lhe um status, aceitá-la. Logo, podemos lidar com ela embora não possamos dissolvê-la, nem tampouco a incerteza, isso indica que devemos pensar com e contra a contradição, quando não sabemos quais contradições são superáveis e quais não o são (ALMEIDA, 2012).

Um passo adiante com Morin, compreendemos que pensar é pensar em movimento aquilo que a lógica clássica pensa de maneira estática, implica complexificar o nosso modo de entender. No processo ensino-aprendizagem, isso implica que nos situemos além do conceito estático e entremos no espaço do macroconceito, ou espaço da conceitualização complexa. O macroconceito valoriza o dinâmico, o que flui, por isso, o estudo de uma realidade ou o objeto passa a ser compreendido como sendo um sistema-organização.

Pensar via macroconceitos é situar-se para além do pensamento monológico, fechado, estático, porque mais relacional, móbil e generativo. Macroconceituar é fazer emergir formas globais, não totalidades fechadas como os atuais conceitos de homem, sociedade, conhecimento, subjetividade, proposto pelo paradigma cartesiano. Se esses forem entendidos como macroconceitos resgata-se sua complexidade, serão sistemas organizativos, produtos de inter-relação, de constelações conceituais, foras das quais se volatizam, desaparecem. Pensar o macroconceito sociedade, por exemplo, exige (inter)relacioná-lo com outros conceitos como sujeito e cultura, em sua enorme complexidade; pensar o macroconceito identidade exige relacioná-lo aos conceitos de organização e interação; o mesmo acontece com o macroconceito homem que deve ser relacionado a espécie/sociedade/cultura/história/subjetividade. Fora isso, os pedagogismos, socialismos, culturalismos e psicologismos são expressões da precariedade teórica e conceitual, e indicam que a redução dos macroconceitos e sua complexidade, e com isso, também boa parte do que é humano, porque passam a ser situados num pensar segundo esquemas simplificadores.

Via macroconceitos amplia-se a noção de conhecimento, que aproxima saberes numa representação rizomática, o que faz com que a linearidade sucumba à vertigem da espiral ao construir pontes entre os saberes eruditos e populares, racionais e emocionais, leigos e teológicos. A lógica da produção deste conhecimento - o pertinente - está em movimento, suas "verdades" serão sempre provisórias e históricas. Conforme a epistemologia do pensamento complexo, o conhecimento não é absoluto, a incerteza é seu maior potencializador, o que amplia dimensões de análises, provoca novas descobertas e possibilidades. Em Morin (1998, p. 236-237) tem-se que: 
[...] Toda introdução da contradição e da incerteza pode transformar-se em ganho de complexidade; é nesse sentido que a limitação trazida pela física quântica ao conhecimento determinista/mecanicista se transforma em ampliação complexificadora do conhecimento e adquire um sentido plenamente epsitemológico.

No campo da Teoria da Complexidade, a incerteza e a forma como ela se faz presente na vida dos sujeitos é descrita a partir do ponto de vista da Física. Por essa natureza, a incerteza é introduzida na previsão do futuro, demonstrando o caráter não determinista da história humana, valorizando o que Prigogine (1996, p. 26) afirmou: "o acontecimento mais insignificante pode mudar o curso da história". Morin (2007) afiança essa observação ao dizer que a ação humana, por exemplo, é sempre uma aposta, pois não se sabe o que ela pode gerar. A ação humana é complexa e remete sempre a outras noções como o aleatório, o improvável, o acidental, o singular, o concreto e o histórico. Não pode ser entendida como uma produção pensável, como afirmado pela lógica cartesiana e da estatística, como simples elemento; ao contrário, possui um caráter singular e fenomenal; é crise, contingência, podendo transformar, modificar, destruir, desenvolver-se a partir de encontros, interações, organizações, o que coloca novamente a incerteza no cerne da vida dos sujeitos e, portanto, da produção do conhecimento.

Resgata-se, assim, a biopsicossociogênese do conhecimento humano, o que significa dizer que se tem um conhecimento inscrito na corporeidade humana (MORAES; VALENTE, 2008, p. 16). Além disso, essa produção do conhecimento tende a favorecer a produção de uma ciência aberta, contextualizada, ecologizada, por isso, como já afirmamos, pertinente.

Para Morin (2007, p. 38-39), o conhecimento pertinente pode e deve enfrentar a complexidade, o que acontece na conjunção de princípios de inteligibilidade que vinculados uns aos outros, e em interlocução, podem promover o pensamento complexo, e com ele a visão complexa do universo. Morin (1999) define os "princípios-guia" da complexidade, eles são interdependentes e complementares: 1) Princípio Dialógico estabelece a articulação entre diferentes lógicas, assumindo as relações paradoxais, conflitivas e de tensão entre partes e todo, mas sem priorizar uma lógica em detrimento da outra. No que tange à educação, este princípio favorece o entendimento das contradições como indissociáveis, acolhe a insuperabilidade como possibilidade, e a incerteza como diretriz para a construção do pensamento complexo. Digamos que seja essencial saber conviver com a articulação de diferentes lógicas e a incerteza, e mesmo assim, conseguir conceber a organização do pensamento. 
Na perspectiva do Princípio Sistêmico-Organizacional, um sistema é uma unidade global organizada por inter-relações (MORIN, 1997), diz respeito ao conhecimento das partes, ao conhecimento do todo, concebendo a relação de interdependência entre eles. No que tange à educação, este princípio exige que o ensinar valorize a dimensão poética, ética, utópica, filosófica, histórica, social e cultural do conhecimento, gerando a possibilidade de promover uma "inteligência geral apta a referir-se ao complexo, ao contexto, de modo multidimensional e dentro da concepção global" (MORIN, 2007, p. 38-39).

O Princípio Hologramático indica que assim como as partes estão inscritas no todo, o todo também está inscrito nas partes, o que torna visível o aparente antagonismo entre partes e todo. Pensando a educação, este princípio pode ajudar a compreender que conhecer o todo somente a partir da separação, simplificação e redução das partes é impossível. Tampouco, podemos negligenciar as partes em detrimento de um todo homogêneo. Para conhecer qualquer objeto de estudo, o pensamento complexo exige sua contextualização, isso inclui as relações de reciprocidade e inter-retroações entre partes e todo, entre diferentes sistemas, e entre relações causais retroativas e recursivas (MORIN, 2007), o que gera o Princípio do Circuito Retroativo e o Princípio do Circuito Recursivo.

O primeiro refere-se aos processos autorreguladores, rompendo definitivamente com o princípio da causalidade linear, porque a causa age sobre o efeito e o efeito sobre a causa. No que diz respeito à educação destaca-se a importância do feedback como retroalimentação durante a produção de conhecimento (MORIN, 2007). O segundo, Princípio Recursivo ou Recorrente refere-se ao circuito gerador, no qual produtos e efeitos são causadores e produtores do que se produz. É este princípio que também ajuda a negar a criação de novos sistemas por determinação linear, mas como processos em circuitos, de modo que os efeitos retroagem sobre as causas desencadeadoras, gerando o entendimento que o circuito não é uma amarra, mas um processo de transformação.

Esse é um aspecto importante para a educação, para a produção do conhecimento, o entendimento de ciência, pois gera a compreensão que a constituição de um novo campo de saber não se constitui apenas "abrindo as fronteiras, mas transformando aquilo que gera as fronteiras, ou seja, os princípios de organização do próprio saber" (MORIN, 2008, p. 466). Somente assim a produção do conhecimento pode ser representada graficamente pela espiral, cujos produtos e efeitos são, eles próprios, produtores e causadores daquilo que os produz, ultrapasse-se, assim, a ideia de regulação, avançando para a de autoprodução e auto-organização (MORIN, 1996, 2002a, 2002b, 2002c).

Para a teoria da complexidade, a auto-organização relaciona-se à capacidade dos sujeitos de criarem novas estruturas, pressupõe a capacidade que um sistema tem de se autoproduzir. Os seres vivos, os sujeitos e as sociedades 
são auto-organizadores e não param de se autoproduzirem. Um exemplo dessa autoprodução pode ser observado quando os sujeitos produzem a sociedade nas e pelas inter-relações, e a emergência da sociedade produz a humanidade dos mesmos (autoprodução e auto-organização) fornecendo-lhes a linguagem e a cultura. No caso da educação, como afirma Arnt (2012), sem o movimento de auto-organização a desordem pode se instalar, gerando estados de incompreensão, ou de ansiedade.

Ao se autoproduzirem os sujeitos possuem uma autonomia que se fundamenta na dependência do meio ambiente. Neste sentido, precisam ser concebidos como autoeco-organizadores, o que gera o Princípio da Autonomia/ Dependência ou Auto-Organização, segundo o qual o conceito de autonomia é complementar ao de dependência e, ao mesmo tempo, antagônico. Fala-se de uma autonomia que se constrói em termos relacionais e relativos, distanciando-se, portanto, de uma liberdade absoluta emancipada de qualquer dependência (MORIN, 1996, 2002a).

Ainda há o Princípio da Reintrodução do Conhecimento em Todo Conhecimento, todo conceito, toda teoria, toda ciência deve comportar dupla ou múltiplas entradas, com a viabilização do duplo foco (objeto/sujeito). A proposta é que se forme um circuito que ajuda no entendimento do como o sujeito revela a percepção da teoria científica. No que toca à educação, este princípio favorece a avaliação do rigor do processo ensino-aprendizagem, resgatando o entendimento que todo o conhecimento é dinâmico, aberto a novos conteúdos. Afinal, produzir conhecimento implica na reconstrução de um conhecimento prévio, simplesmente porque não podemos descartar nossa historicidade.

Esse princípio também exige fazer idas e vindas incessantes entre certezas e incertezas, entre o elementar e o global, entre o separável e o inseparável, mas não só; espera-se incorporar os princípios de ordem, de separabilidade e de lógica, integrá-los em uma concepção mais rica, o que seria o mesmo que efetivar as complementaridades. A premissa é aspirar uma produção de conhecimento não fragmentada, não compartimentada, não redutora, reconhecendo-se seu aspecto inacabado e sua incompletude (MORIN, 2002a, 2002c).

Os princípios ou operadores cognitivos do pensamento complexo têm sido apresentados e discutidos de várias formas, além de já serem complementados, como no caso de Moraes (2008), que somou àqueles o Princípio Ecológico da $A c ̧ a ̃ o$, mas o importante é não imaginá-los isolados uns dos outros, devemos lembrar que todos estão interligados e atuam de modo sinérgico.

Como instrumentos de articulação, os operadores cognitivos ajudam sair da linearidade habitual para enriquecer nossa capacidade de encontrar soluções, criar novas perspectivas, desenhar novos cenários e tomar decisões. Gradativa- 
mente, também ajudam a restaurar nossa visão linear, desenvolvida ao longo de pelo menos três séculos de pensamento fragmentado.

Por outro ângulo, conforme comentário de Boaventura Santos (2004a, 2004b), gera-se uma transformação que pode fazer com que a ciência caminhe para os estudos humanísticos que transformem a distinção sujeito/objeto; que introduza a consciência no ato do conhecimento e no próprio objeto do conhecimento; que promova a visão do conhecimento como busca da totalidade universal, em contraste com a excessiva disciplinarização do saber científico, e que admita a pluralidade metodológica e a tolerância discursiva, o que pode resultar em abordagens transdisciplinares.

Esse é outro aspecto complementar ao atual paradigma, a transdisciplinaridade, conforme Nicolescu $(2000,2003)$, tem no prefixo trans o significado do que está ao mesmo tempo entre as disciplinas, através delas e além de qualquer uma delas. A transdisciplinaridade está para o mundo acadêmico, pois se preocupa com o conhecimento, sua atual organização em disciplinas, superposições e espaços vazios entre elas, assim como seus pontos de interlocução e complementaridade.

Por isso, a transdisciplinaridade se configura como processo de abertura para a compreensão da realidade; sugere uma disponibilidade para dialogar com formas de produção de conhecimento diferenciadas; é multirreferencial, dialoga com a Ciência e com outras lógicas, como a Tradição, a Mitologia, a Arte, a Filosofia e a Religião, sempre procurando estabelecer zonas de intersecção.

O objetivo da transdisciplinaridade, segundo Nicolescu (2001, p. 51), é a compreensão do mundo presente, "encoraja a reconciliação das diferentes áreas do conhecimento, não exclui a disciplinar, uma vez que elas não são antagônicas, mas complementares". Não ambiciona o "domínio de diferentes disciplinas, mas tem como objetivo abrir todas as disciplinas para o que elas podem compartilhar e para o que reside além delas" (NICOLESCU, 2002, p. 149).

Por isso considera que os limites entre as diferentes áreas do conhecimento, ou seja, as disciplinas, são abundantes de informações e possibilidades a serem exploradas, pois nenhum modo de conhecimento pode abarcar toda a realidade, não existe uma ciência (única) capaz de explicar todos os processos envolvidos na história dos seres vivos humanos. No campo da educação, almeja um modo de tratamento global, não redutor dos processos, que desenvolva uma postura interna adequada à necessidade de rigor científico, abertura e tolerância para os vários pontos de vista e aspectos da produção do conhecimento, o que discutiremos logo mais.

Como o paradigma da complexidade exige processos democráticos de escolha e de envolvimento, é conveniente afirmar que pede a construção da atitude transdisciplinar entre os sujeitos (MAGALHÃES, 2011), ancorada em uma metodologia embasada em três pilares: 1) o reconhecimento dos vários ní- 
veis de realidade, 2) complexidade do mundo e, 3) a lógica do terceiro incluído. Conforme Nicolescu (2002), estes pilares auxiliam a transição paradigmática, logo, a transformação do conhecimento.

Com o primeiro pilar entendemos que a passagem de um nível de realidade a outro se dá pelo conhecimento, o que implica na existência de uma realidade que possui diferentes níveis ou estágios de organização, quanto diferentes níveis de percepção para poder conhecê-la, o que influencia o nível de consciência na relação sujeito/objeto. Nicolescu (2002) afirma que existem, hoje, pelo menos, três níveis de realidade: a realidade macrofísica (da escala supra-atômica), a microfísica (escala subatômica) e a realidade virtual, todas elas têm como suporte as experiências, representações, interpretações, descrições, imagens e formalizações matemáticas. Cada nível é regido por leis e regras diferentes (MORAES, 2008).

Para cada nível de realidade há um nível de percepção desta realidade, havendo, conseqüentemente, infinitos níveis de percepção, alinhados aos níveis de realidade. São os diferentes níveis de percepção que nos apresentam a multirreferencialidade do real, ao estabelecerem relações entre o objeto observado e o observador. Lembro que o observador transforma o observado com sua observação, vislumbra-se a partir daí os desdobramentos da relação intrínseca entre nível de percepção e nível de realidade (ARNT, 2007, p. 106).

No segundo pilar a complexidade está presente na natureza da vida e das coisas em todas as partes, como já discutimos. No caso da educação, a influência da complexidade pode pulverizar a pirâmide das disciplinas, o que exigiria redirecionar os currículos propostos nos cursos de formação, buscando-se entender que cada disciplina é um todo e é parte de um todo do conhecimento integral (NICOLESCU, 2000, p. 21-24).

Quanto ao terceiro pilar, em Nicolescu (2000, p. 29) temos que em termos matemáticos a lógica clássica exclui a possibilidade de articulação, sendo a lógica quântica que introduz inovações. Ela altera a lógica clássica ao definir um terceiro termo incluído, mas para articulá-lo, pressupõe-se a existência de outro nível de realidade, diferente do nível anterior da lógica clássica ou da não contradição.

Este terceiro pilar está descrito no Artigo 14 da Carta da Transdisciplinaridade, afirma-se que ele é articulado por meio do rigor, abertura e tolerância, características fundamentais da atitude e da visão transdisciplinar. A lógica do 
terceiro incluído exige rigor na argumentação que necessita levar em conta todos os dados e/ou possíveis distorções; a abertura comporta a aceitação do desconhecido, do inesperado e do imprevisível; e a tolerância visa o reconhecimento do direito às ideias e verdades contrárias às nossas.

A complementaridade desses três pilares da transdisciplinaridade ao atual paradigma da produção do conhecimento, o que inclui o ensino de Psicologia da educação, passa pela reorganização dos saberes, e isso exige:

[...] diálogo e sua reconciliação não somente com as ciências humanas, mas também com a arte, a literatura, a poesia e a experiência espiritual. Encontramos aqui a referência para a construção de conhecimento a partir da metodologia científica, mas, sem se restringir a ela, buscando recursos e estratégias na criação artística, possibilitando o desenvolvimento do senso estético, da expressão em diferentes linguagens [...] (ARNT, 2007, p. 4).

A reorganização dos saberes ainda passa pela reflexão, hibridação, heterogeneidade, e não linearidade, o que fomenta novas formas transdisciplinares de estudar o homem e sua realidade e, em longo prazo, favorece o processo de (trans)formação dos sujeitos.

Formar os sujeitos nos termos do paradigma da complexidade envolve uma educação in vivo ${ }^{5}$, a qual gera uma nova estética de trabalho, sobretudo no campo da formação de professores, pois busca articular dois movimentos: (re)ligação a si mesmo e (re)ligação ao outro (pessoas, conhecimento, cultura, natureza, vida). Abre-se a possibilidade de uma nova visão da realidade (FREIRE; SHOR, 1986; FREIRE, 1997b; CONTRERAS, 1997; VEIGA; RESENDE; FONSECA, 2002; VEIGA; CASTANHO, 2002; CUNHA; LUCARELLI, 2007).

\section{O ensino de Psicologia: refletindo sobre os benefícios da base epis- temológica da complexidade em Morin}

É possível entender que o paradigma da complexidade exige a libertação do conhecido ranço cartesiano que tem envolvido as práticas pedagógicas, bem

${ }^{5}$ A proposta foi apresentada por Nicolescu no Congresso Internacional - Que Universidade para o Amanhã? Em busca de uma evolução transdisciplinar para a universidade, em Locarno, na Suíça, em 1997. 
como o abandono da limitada zona da certeza tradicional que tem envolvido o ensino de Psicologia, sobretudo no contexto da formação de professores.

A partir de uma visão complexa, o ensino de Psicologia não é aqui compreendido como uma prática instrumental, mas como definido por Anastasiou e Pessate (2009), um ato de ensinar que se relaciona à ação de apreender que se constitui num processo de mútua determinação, denominado pela autora como processo de ensinagem.

Segundo Pimenta e Anastasiou (2005) é preciso diferenciar o conceito de aprender e apreender, aprender liga-se a uma concepção instrumental de educação, pois refere-se à ação de receber a informação e retê-la na memória mediante uma ação pedagógica tradicional, como se o aluno fosse um receptáculo, no qual o professor verte conhecimento. $\mathrm{O}$ apreender implica ação, participação, significa apropriar-se do conhecimento.

$\mathrm{O}$ processo de ensinagem refere-se a um ensinar e um apreender como unidade dialética, onde o aluno é sujeito da aprendizagem que troca, constrói, cria, reflete, e critica, numa relação intersubjetiva que proporciona trocas simbólicas entre os sujeitos envolvidos (ANASTASIOU; PESSATE, 2009). Ainda acrescenta-se que o processo de ensinagem envolve um ato profissional efetivado por aqueles que professam e exercem a docência, socializando o conhecimento, atuando como mediadores entre a aprendizagem dos estudantes e os desafios próprios à fase do curso em que atuam, envolve intencionalidade definida e assumida pelos sujeitos envolvidos no processo.

Assim entendendo, mesmo utilizando a palavra ensino de Psicologia neste texto, referimo-nos ao processo de ensinagem, no qual o fazer pedagógico procura favorecer a construção de um conjunto de conhecimentos inter-relacionados que sirvam aos propósitos de articular teoria e prática como conteúdo e forma, oferecendo elementos para a práxis, ou prática pedagógica complexa (MERCURI; BATISTA; SOARES, 1999; ALMEIDA, 1999).

Com a abertura necessária é possível aceitar a complementaridade advinda da Teoria da Complexidade e, a partir daí, rever alguns conceitos propostos pelo campo da Psicologia. Esse referencial sugere reconceitualizações de importantes categorias analíticas para a Psicologia: o pensar por meio de macroconceitos, o conhecimento, a educação, como já discutimos, e, ainda, homem, realidade, autonomia, identidade, subjetividade, e razão, o que pode ser extremamente produtivo no sentido de ajudar a considerar os múltiplos aspectos que envolvem o objeto de estudo da Psicologia, sobretudo no campo da formação docente.

Ontologicamente a visão complexa de homem explicita um ser não dicotomizado, com natureza multidimensional íntegra, capaz de superar a fragmentação do saber (da própria vida) via pensamento complexo, o que lhe possibilitará ir além das perspectivas limitadoras. Esta visão resgata o potencial humano, 
corpo e espírito, cérebro e mente, com todo o seu patrimônio hereditário, inato e adquirido, de natureza física, biológica, psíquica, social, cultural, pois, de acordo com Behrens (2012), o homem é visto de uma maneira articulada, mergulhando suas raízes na emoção, no sentimento, na sensibilidade.

Morin (1996, 2002a) ainda mostra que o homem tem uma base bio-lógica correspondendo à lógica própria do ser vivo. É considerado um sistema, uma unidade e multiplicidade a um só tempo, é unidade múltipla. É um sistema vivo a um só tempo, aberto e fechado. Aberto, pois necessita de informações novas do meio ambiente para continuar seu processo de amadurecimento, de crescimento e de desenvolvimento, enquanto unidade e multiplicidade; fechado, pois necessita preservar sua identidade, singularidade e originalidade, seu modo de viver (MORIN, 2002a, 2002b).

É preciso perceber a relação de antagonismo, de concorrência e de complementaridade presente na definição do sujeito moriniano, principalmente entre estas duas noções: sistema aberto e fechado, pois não há exclusão da abertura do sistema vivo em detrimento de seu fechamento ou vice-versa. Essa compreensão amplia a noção de homem (ser, sujeito) desenvolvido pelo ensino de Psicologia, pois é norteadora de uma análise do "ser" numa perspectiva multidimensional, ou seja, se já se discutia o homem a partir das dimensões - social, emocional, econômica, política, histórica - passa-se a pensá-lo também a partir da ecológica, mística, espiritual e cósmica. O homem passa a ser considerado como homo sapiens/demens, homo complexus, um ser paradoxal, uno e múltiplo ao mesmo tempo, que se constrói dialogando com a diversidade de influências experimentadas.

É necessário observar que a concepção complexa da natureza humana em Morin (1999, p. 95) diferencia-se das concepções humanistas tradicionais. Para entendê-la se faz necessário que utilizemos o princípio dialógico, para entender a posição do autor que se coloca ao mesmo tempo como um "anti-humanista" e um humanista do século XXI. Primeiro, ele assume que as críticas feitas ao humanismo clássico, dos pontos de vista filosófico, político e epistemológico, se justificam, pois o homem não é o único sujeito num universo de objetos que tem como ideal a conquista do mundo, por estar totalmente separado da natureza. Ao contrário do pensamento cartesiano, Morin sustenta a tese que não há como dissociar o homem da natureza, sua investigação só pode ser concebida por meio de uma antropocosmologia que deixa para trás a associação estrita entre o homo sapiens e o desenvolvimento da razão. Com a antropocosmologia relaciona-se o destino do homem ao destino do cosmo, sustentando-se uma concepção complexa da natureza humana, que diz respeito a um humanismo hominizado (MORIN, 1999), como resultado das múltiplas interações do próprio homem com o ecossistema. 
A representação de homem elaborada pela teoria da complexidade choca-se com o que Morin chama de humanismo racionalista, que visa eliminar a loucura e as afetividades mais impulsivas como desvios que não fazem parte da constituição do homo sapiens. Conforme Morin, o homem não se constitui só em sapiens e faber, mas carrega em si também o demens, por isso complexus.

Entendido como sistema dependente do meio com o qual produz processos de troca, renovação e transformação (sistema aberto e fechado); o homem é um ser autônomo que se abre e troca, renova e transforma-se na inter-relação com outros sistemas vivos, e quando se fecha, define assertivamente o que é seu e o que é dos outros (MORIN, 2007, 2002b). Pode-se afirmar que os sujeitos desenvolvem sua autonomia, na dependência de sua cultura e vice-versa, e nesse processo, percebem sua identidade e singularidade, o que só é possível por meio das fronteiras que são abertas e os conectam com o meio ao qual pertencem.

Nessa rota, ao definir o que é seu e do outro, o sujeito também define sua identidade, outra importante contribuição ao campo da Psicologia. Segundo Morin (1996, p. 49), a identidade comporta um princípio de distinção, de diferenciação e de reunificação, o que possibilita aos sujeitos a capacidade de referir-se ao mesmo tempo a "si" (autorreferência) e ao mundo exterior (exorreferência).

Portanto, o processo de formação da identidade é denominado por Morin de autoexorreferência, constitutivo da identidade subjetiva, o que permite aos sujeitos operarem a distinção entre o eu e o não eu, ou seja, o meu eu e os outros eus o que possibilita a unidade e invariância a uma pluralidade de personagens. O princípio de identidade complexo, denominado unitas multiplex, mostra que o sujeito se define como uma produção singular mediante ações, inter-relações e recursões entre as partes e o todo do sistema, e entre este e o meio do qual faz parte - a cultura.

Portanto, a identidade é compreendida como fenômeno sistêmico. Lembramos que no entendimento de Morin (2007, p. 260) "um sistema não é só uma constituição de unidade a partir da diversidade, mas também uma constituição de diversidade (interna) a partir da unidade". Do que se entende que a identidade é produzida via cultura comum para sujeitos diversos, mas que também permite o desenvolvimento das diferenças por meio da própria cultura, de símbolos e de mitos. Teremos um sujeito que é único e a individualidade não é apenas diferença e singularidade, mas também subjetividade constituída via intersubjetividade.

A noção de subjetividade na ótica de Morin é mais uma contribuição ao campo da Psicologia, pois é compreendida como um vir-a-ser aleatório produzido em uma rede de sistemas interdependentes, ou seja, na trama de inter-relações, de grupos sociais, culturais e biológicos. Para Morin, a subjetividade não é o ser, sua raiz, tampouco sua essência, mas sim, a capacidade de receber o sentido, de fazer algo com ele, produzir sentido, dar sentido. Ela é possibilidade do sujeito, 
emergência produzida na inter-relação entre o social, o cultural e o biológico; é uma experiência fenomenal, individual e coletiva a um só tempo (MORIN, 1996, 2007, 2002b).

Quanto à razão, outra contribuição ou complementaridade ao campo da Psicologia, a complexidade abre as portas da lógica da articulação e da abertura frente à lógica do fragmento. Um entendimento importante é que não se pode superar os princípios da lógica clássica, mas não é menos verdade que não podemos pensar construir apenas com eles. O pensamento complexo, criativo e criador prescindi de uma lógica que se liga à razão aberta, paradigmaticamente dialógica.

Para o pensamento complexo, a razão é o aspecto lógico que corresponde à visão coerente dos fenômenos, das coisas e do universo, que deve manter diálogo permanente com a coerência, o que inaugura a razão aberta. Esta razão aberta se caracteriza por ser evolutiva, residual, complexa e dialógica.

É residual porque acolhe o a-racional e o sobre-racional. É complexa porque reconhece a complexidade da relação sujeito/objeto, ordem/ desordem, reconhecendo, também em si própria, uma zona obscura, irracional e incerta, abrindo-se ao acaso, à álea, à desordem, ao anômico e ao a-estrutural. É dialógica porque opera com macro-conceitos recursivos, ou seja, grandes unidades teóricas de caráter complementar, concorrente e antagonista (ESTRADA, 2004, p. 10, grifos da autora).

A razão aberta revela sérios limites da razão fechada, diga-se instrumental, cujos princípios - a simplificação, a generalização e a disjunção - encaminham inevitavelmente a um pensamento incompleto, que separa o sujeito do objeto e este do seu ambiente. Se nos voltarmos novamente para a educação, a razão fechada elimina a incerteza, o erro, a ambiguidade, o contraditório, a complexidade do real; e no caso da produção do conhecimento que assim como a razão é evolutivo progredindo por mutações e reorganizações profundas, há de ser correto pensar que a razão aberta pode transformar o próprio pensamento, ajudando-nos a superar modelos e teorias reducionistas que decididamente legitimamos.

A instabilidade gerada por essa proposta pode representar uma ótima oportunidade, primeiro por permitir o desenvolvimento do nosso potencial criativo, até então sobre rígido controle. Sabe-se que onde há muito controle, não há criatividade. Ao considerar esse mesmo movimento nos contextos educativos tem-se que "o todo é mais do que uma realidade global, é um dinamismo 
organizacional" (MORIN, 2007, p. 261) que acaba definindo a práxis do viver, da (auto)eco-organização, das trocas e do comportamento do sistema vivo no meio ambiente.

A intervenção dos pressupostos da complexidade até aqui discutidos caracteriza uma percepção singular do conteúdo proposto no processo de ensinagem de Psicologia. Ela caminha por percepções mais dialógicas, sistêmicas, hologrâmicas, transdisciplinares e complexas. É Morin (2007, p. 180-181) quem afirma que estamos diante da necessidade de "pensar em conjunto na sua complementaridade, na sua coerência e no seu antagonismo as noções de ordem, de desordem e de organização, isso obriga-nos a respeitar a complexidade física, biológica, humana". Infelizmente, "[...] esquemas simplificadores dão lugar a ações simplificadoras e esquemas unidimensionais, dão lugar a ações unidimensionais" (MORIN, 2002a, p. 47), o mundo poderia ser melhor, se os homens não agissem e nem pensassem apenas linearmente.

Finalizamos entendendo que a contribuição da Teoria da Complexidade não passa somente pela intelectual, mas por uma nova forma de compreender a dimensão humana, por um processo de empatia, de identificação e de projeção intersubjetiva (MORIN, 2007). Ainda há muito que pensar sobre as mudanças que a teoria pode gerar no ensino de Psicologia, por agora é necessário iniciar o movimento, talvez, perceber que a crise (paradigmática) também pode ser uma grande possibilidade de transformação.

\section{REFERÊNCIAS}

ALMEIDA, C. Conviver com as incertezas. In: MAGALHÃES, S. M. O.; SOUZA, R. C. C. R. de. Formação de professores - Elos da dimensão complexa e transdisciplinar. Goiânia: Liber, PUC-GO, 2012.

ALMEIDA, C.; PETRAGLIA, I. Complexidade e formação: algumas ideias norteadoras. In: ALMEIDA, C.; SEVERINO, A. J.; LORIERI, M. A. (Orgs.). Perspectivas da filosofia da Educação. São Paulo: Cortez, 2011.

ALMEIDA, P. C. A. A prática pedagógica junto a alunos adolescentes: as contribuições da psicologia. 150 f. Dissertação (Mestrado em Educação: Psicologia Educacional) Universidade Estadual de Campinas, Campinas, 1999.

ANASTASIOU, L. G. C.; PESSATE, A. L. In: . Processos de Ensinagem na Universidade: pressupostos para as estratégias de trabalho em aula. 8. ed. Joinville: Editora Univille, 2009. 
ARNT, R. de M. Cenários transdisciplinares na formação inicial de professores. Docência transdisciplinar: em busca de novos princípios para ressignificar a prática educacional. Tese (Doutorado) - Programa de Pós-Graduação em Educação, PUC/SP, São Paulo, 2007.

. Cenários transdisciplinares na formação inicial de professores. In: MAGA$\overline{\text { LHÃES}}$, S. M. O.; SOUZA, R. C. C. R. de. Formação de professores - Elos da dimensão complexa e transdisciplinar. Goiânia: Liber, PUC-GO, 2012.

ARRUDA, M. Humanizar o infra-humano: a formação do ser humano integral: homo evolutivo, práxis e economia solidária. Petrópolis: Vozes, 2003.

ASSMANN, H. Reencantar a Educação - rumo à sociedade aprendente. Petrópolis: Vozes, 1998.

BEHRENS, M. A. Docência universitária no paradigma da complexidade: caminho para a visão transdisciplinar. In: MAGALHÃES, S. M. O.; SOUZA, R. C. C. R. de. Formação de professores - Elos da dimensão complexa e transdisciplinar. Goiânia: Liber, PUC-GO, 2012.

. O paradigma emergente e a prática docente. Petrópolis: Vozes, 2005.

. O paradigma da complexidade: metodologia de projetos, contratos didáticos e portifólios. Petrópolis: Vozes, 2006.

BOURDIEU, P. A economia das trocas simbólicas. 5. ed. São Paulo: Perspectiva, 2001.

BRASIL. Comitê Nacional de Educação em Direitos Humanos. Plano Nacional de Educação em Direitos Humanos. Brasília: Secretaria Especial dos Direitos Humanos/ Ministério de Educação/Ministério de Justiça/UNESCO, 2007.

CAPRA, F. A Teia da Vida - uma nova compreensão científica dos sistemas vivos. Trad. de: Newton Roberval Eichemberg. São Paulo: Cultrix, 2000.

. Ponto de mutação. São Paulo: Cultrix, 1997.

CHAUÍ, M. A universidade pública sob nova perspectiva. Rev. Bras. Educ., n. 24, p. 5-15, 2003.

CONTRERAS, J. D. La autonomia del profesorado. Madrid: Morata, 1997.

CUNHA, M. I.; LUCARELLI, E. Inovações na sala de aula universitária e saberes docentes: experiências de investigação e formação que aproximam Argentina e Brasil. In: CONGRESSO INTERNACIONAL DE ESTUDOS COMPARATIVOS EM EDUCAÇÃO, Anais... Argentina, 2007.

DELORS, J. Educação: um tesouro a descobrir. São Paulo: Cortez, 2000.

ESTRADA, A. A. A crise dos paradigmas e a educação. Educere, Umuarama, v. 4, n. 1, p. 5-18, 2004.

FREIRE, P. A educação do futuro. Caderno Prosa \& Verso de O Globo, Rio de Janeiro, 24 maio 1997a. 
. Pedagogia da autonomia: saberes necessários à prática educativa. 15. ed. São Paulo: Paz e Terra, 2000.

. Pedagogia da esperança. Um reencontro com a pedagogia do oprimido. São Paulo: Paz e Terra, 1997b.

. Pedagogia do oprimido. Rio de Janeiro, RJ: Paz e Terra, 1996.

FREIRE, P.; SCHOR, I. Medo e ousadia. O cotidiano do professor. Rio de Janeiro: Paz e Terra, 1986.

GADOTTI, M. Perspectivas atuais em educação. Porto Alegre: Artmed, 2000.

GUARESCHI, P. A. Pressupostos Metafísicos e Epistemológicos na Pesquisa. Psicologia: Reflexão e Crítica, v. 16, n. 2, p. 245-255, 2003.

JARES, X. R. Educação para a paz: sua teoria e sua prática. Trad. de: Fátima Murad. 2. ed. rev. e ampl. Porto Alegre: Artmed, 2003.

KUHN, T. S. A Estrutura das revoluções cientificas. São Paulo: Perspectiva, 1996.

LUCARELLI, E. Teoría y práctica como innovación en docencia, investigación y actualización pedagógica. Cuaderno de Investigación, n. 10. Bs. As. UBA. p. 14. FFyL. IICE, 1997.

MAGALHÃES, S. M. O. Afetar e sensibilizar na Educação: uma proposta transdisciplinar. Revista Linhas Críticas, Faculdade de Educação, Universidade de Brasília, v. 17, n. 32, 2011.

MARTÍN, X.; PUIG, J. As sete competências básicas para educar em valores. Trad. de: Óscar Curros. São Paulo: Summus Editorial, 2010. 182 p.

MARX, K.; ENGELS, F. The german ideology. 6. ed. New York: International, 1977.

MERCURI, E. N. G. S.; BATISTA, S. H. S. S.; SOARES, C. L. O Ensino de Psicologia na Licenciatura: o ponto de vista de egressos de uma universidade pública. In: REUNIÃO ANUAL DE PSICOLOGIA, XXIX, Campinas, 1999. Anais da Sociedade Brasileira de Psicologia, p. 137, out. 1999.

MORAES, M. C. Complexidade e currículo: por uma nova relação. Polis [En línea], n. 25, 2010, Puesto en línea el 23 abril 2012.

. Ecologia dos Saberes: transdisciplinaridade, complexidade e educação. São Paulo: ProLíbera Editora: Antakarana/WHH - Willis Harman House, 2008.

. Educar na biologia do amor e da solidariedade. Petrópolis/RJ: Vozes, 2003.

MORAES, M. C.; VALENTE, J. A. Como pesquisar em educação a partir da complexidade e da transdisciplinaridade? São Paulo: Paulus, 2008.

MORIN, E. A cabeça bem-feita: repensar a reforma, reformar o pensamento. 7. ed. Rio de Janeiro: Bertrand do Brasil, 2002a. 
. A noção de sujeito. In: SCHNITMAN, D. F. (Org.). Novos paradigmas, cultura e subjetividade. Porto Alegre: Artes Médicas, 1996. p. 45-58.

. Amor, poesia, sabedoria. Rio de Janeiro: Bertrand Brasil, 2001.

. Ciência com consciência. 6. ed. Rio de Janeiro: Bertrand do Brasil, 2002b.

. Complexidade e transdisciplinaridade: a reforma da universidade e do Ensino Fundamental. Natal: EdufRN, 1999.

. Meus Demônios. Rio de Janeiro: Bertrand Brasil, 1997.

. O método 1: a natureza da natureza. Porto Alegre: Sulina, 2008.

. O método 5: a humanidade da humanidade. Porto Alegre: Sulina, 2002c.

. Os sete saberes necessários à educação do futuro. São Paulo: Cortez; Brasília, DF: UNESCO, 2007.

. Terra-pátria. Porto Alegre: Sulina, 1995.

NICOLESCU, B. A prática da transdisciplinaridade. In: . (Org.). Educação e transdisciplinaridade. Brasília: UNESCO, 2000.

. Educação e Transdisciplinaridade, II. São Paulo: TRIOM, 2002. p. 45-70.

. Fundamentos Metodológicos para o Estudo Transcultural e Transreligioso. In: . O Manifesto da transdisciplinaridade. São Paulo: Triom, 2001.

. Transdisciplinaridade. Porto Alegre: PPGA/EA/UFRGS, 2003.

. Transdisciplinarity: past, present and future. 2006. Disponível em: $<$ http:// www.scribd.com/doc/17676820/Basarab-Nicolescu-TRANSDISCIPLINARITY-PAST-PRESENT-AND-FUTURE>. Acesso em: 01/09/2012.

PIMENTA, S. G.; ANASTASIOU, Léa das G. C. Docência do ensino superior. 2. ed. São Paulo: Cortez, 2005.

PETRAGLIA, I.; VASCONCELOS, A. F. de C. Educação e ética planetária. Cadernos de Pós-Graduação, São Paulo, v. 8, p. 65-74, 2009.

PRIGOGINE, I. “O fim da ciência?”. In: SCHNITMAN, D. F. (Org.). Novos paradigmas, cultura e subjetividade. Porto Alegre: Artes Médicas, 1996. p. 25-44.

PUEBLA, E. Educar com o coração: uma educação que desenvolve a intuição. São Paulo: Petrópolis, 1997.

SANTOS, Boaventura S. Conhecimento prudente para uma vida decente: Um discurso sobre as ciências revisitado. São Paulo: Cortez, 2004a.

. Um discurso sobre as ciências. 2. ed. São Paulo: Cortez, 2004b. 92 p.

SOUZA, R. C. C. de. Universidade processo de ensino aprendizagem e inovação. In: ENCONTRO DE PESQUISA EM EDUCAÇÃO DA ANPED CENTRO-OESTE, 
EDUCAÇÃO TENDÊNCIAS E DESAFIOS DE UM CAMPO EM MOVIMENTO, 9, Brasília: Liber Livro Editora. Anais... ANPED, 2008.

TORRE, S. de La; BARRIOS, O. Curso de formação de educadores: estratégias didáticas inovadoras. São Paulo: Madras, 2002.

VEIGA, I. P.; CASTANHO, M. E. L. M. Pedagogia Universitária: a aula em foco. 3. ed. Campinas, São Paulo: Papirus, 2002. Coleção Magistério: Formação e Trabalho Pedagógico.

VEIGA, I. P.; RESENDE, L.; FONSECA, M. Aula universitária e inovação. In: VEIGA, I. P.; CASTANHO, M. E. L. M. Pedagogia Universitária: a aula em foco. 3 ed. Campinas, São Paulo: Papirus, 2002. Coleção Magistério: Formação e Trabalho Pedagógico.

Texto recebido em 18 de setembro de 2011.

Texto aprovado em 09 de abril de 2013. 